\title{
OPEN Dual-functional quantum-dots light emitting diodes based on solution processable vanadium oxide hole injection layer
}

Tae Yeon Kim¹, Sungho Park' ${ }^{1}$, Byung Jun Kim ${ }^{1}$, Su Been $\mathrm{Heo}^{1}$, Jong Hun $\mathrm{Yu}^{1}$, Jae Seung Shin ${ }^{1}$, Jong-Am Hong ${ }^{2}$, Beom-Su Kim², Young Duck Kim², Yongsup Park ${ }^{2 \bowtie}$ \& Seong Jun Kang ${ }^{1 \bowtie}$

Dual-functional quantum-dots light emitting diodes (QLEDs) have been fabricated using solution processable vanadium oxide $\left(\mathrm{V}_{2} \mathrm{O}_{5}\right)$ hole injection layer to control the carrier transport behavior. The device shows selectable functionalities of photo-detecting and light-emitting behaviors according to the different operating voltage conditions. The device emitted a bright green light at the wavelength of $536 \mathrm{~nm}$, and with the maximum luminance of $31,668 \mathrm{~cd} / \mathrm{m}^{2}$ in a forward bias of $8.6 \mathrm{~V}$. Meanwhile, the device could operate as a photodetector in a reverse bias condition. The device was perfectly turned off in a reverse bias, while an increase of photocurrent was observed during the illumination of $520 \mathrm{~nm}$ wavelength light on the device. The interfacial electronic structure of the device prepared with different concentration $\mathrm{V}_{2} \mathrm{O}_{5}$ solution was measured in detail using $\mathrm{x}$-ray and ultraviolet photoelectron spectroscopy. Both the highest occupied molecular orbital and the gap state levels were moved closer to the Fermi level, according to increase the concentration of $\mathrm{V}_{2} \mathrm{O}_{5}$ solution. The change of gap state position enables to fabricate a dual-functional QLEDs. Therefore, the device could operate both as a photodetector and as a light-emitting diode with different applied bias. The result suggests that QLEDs can be used as a photosensor and as a light-emitting diode for the future display industry.

Photosensor has been considered as a key component of optoelectronics for the next-generation smart device according to the recent development of internet of thing (IoT) technology $y^{1,2}$. Various photosensors could be integrated into IoT circuits to detect a light including infrared, visible, ultraviolet light, and to convert the input light signal into the electrical signal ${ }^{3-5}$. Based on the detection of light, IoT circuits can observe the environmental condition and perform many useful functions, such as an autonomous car, a smart factory, and the next-generation communications ${ }^{6-8}$. Therefore, there are many research efforts to develop a high-performance photosensor based on emerging nanomaterials ${ }^{9,10}$.

Recently, detecting visible-light is considered as the most important function for the IoT photosensor, because of the similarity with human eye and development of artificial intelligence ${ }^{11,12}$. Also, many research groups tried to demonstrate unconventional visible-light photosensors, such as a highly-transparent and multi-functional visible-light photosensors, due to their flexibility for the application in IoT fields ${ }^{13-15}$. Recently, a visible-light photosensor based on a hetero-structure of small band gap quantum-dots and wide band gap oxide semiconductor has been developed ${ }^{16,17}$. A visible-light photosensor base on $2 \mathrm{D}$-nanomaterials have been demonstrated recently by Xiao et al., as well ${ }^{18}$. Although most of the image sensors are composed of photodiodes, recent developments have demonstrated a visible-light phototransistor. Therefore, it is necessary to develop a photodiode, which can detect a visible-light, for the next-generation IoT photosensor.

Meanwhile, quantum-dots light-emitting diodes (QLEDs) have been considered as a next-generation display due to its superior electrical and optical properties than the organic light-emitting diodes ${ }^{19,20}$. Colloidal quantumdots (QDs) are widely used in optoelectronics due to their high stability and durability ${ }^{21}$. Beside, QDs have a tunable band gap by controlling the size of QDs, excellent color purity, and high external quantum efficiency ${ }^{22,23}$. Most of all, QLEDs can be fabricated using a solution process which is favorable for the large-scale display with a low cost in industry. Therefore, QLEDs can be applied to the thin and deformable display with a highperformance for the IoT optoelectronics. Basically, QLEDs and QDs photodiode have a same device structure.

${ }^{1}$ Department of Advanced Materials Engineering for Information and Electronics (BK21 four), Kyung Hee University, Yongin 17104, Korea. ${ }^{2}$ Department of Physics and Research Institute for Basic Sciences, Kyung Hee University, Seoul 02447, Korea. ${ }^{\circledR}$ email: parky@khu.ac.kr; junkang@khu.ac.kr 
The difference of QLEDs and QDs photodiode is the operating condition. Generally, a positive bias is applied for the light-emitting state of QLEDs, while a negative bias is applied for the light-detecting of QDs photodiode ${ }^{24}$. Therefore, dual-functional optoelectronics, which can emit and detect a visible-light, can be fabricated using QDs and allow the developments of smaller and high-performance IoT optoelectronics. However, it is hard to achieve an efficient interfacial electronic structure for the high efficient light emission and photodetection. Therefore, it is important to control the interfacial electronic structure of the device to achieve a dual functional QLEDs.

In this study, we have fabricated and evaluated dual-functional QLEDs that used a solution processable inorganic $\mathrm{V}_{2} \mathrm{O}_{5}$ hole injection layer (HIL). The change of interfacial electronic structure by inserting various concentrations of $\mathrm{V}_{2} \mathrm{O}_{5}$ has been measured using $\mathrm{x}$-ray photoelectron spectroscopy (XPS) and ultraviolet photoelectron spectroscopy (UPS). Based on the interfacial electronic structure, we have optimized dual-functional QLEDs to have a light-emitting and a photo-detecting abilities in a visible range. Time-resolved photoluminescence (TRPL) measurements were performed to confirm the photon-electron energy transfer mechanism. In addition, circuits that can simultaneously generate and exchange electrical signal to optical signal, and vice versa were demonstrated using two dual-functional QLEDs. Therefore, the device can be applicable as a next-generation IoT optoelectronics.

\section{Results and discussion}

In this work, conventional structured QLEDs have been fabricated using a solution processable $\mathrm{V}_{2} \mathrm{O}_{5}$ HIL, and characterized the electrical and optical properties of QLEDs as shown in Fig. 1. The device consists of thin multilayers of ITO/ $\mathrm{V}_{2} \mathrm{O}_{5} / \mathrm{TFB} / \mathrm{QDs} / \mathrm{ZnO} / \mathrm{Al}$, schematic of fabricated QLED is shown in the inset of Fig. 1a. Core/shell structured CdSe/ZnS QDs were used as an emissive layer, while TFB and $\mathrm{ZnO}$ are used as a hole transport layer (HTL) and electron transport layer (ETL), respectively. $1 \mathrm{wt} \%$ of $\mathrm{V}_{2} \mathrm{O}_{5}$ solution has been used to form a thin layer of HIL for the conventional structured QLEDs. Current density and luminance characteristics according to the applied voltage are shown in Fig. 1a. The turn-on voltage was $2.6 \mathrm{~V}$, and the device exhibited the maximum luminance of $31,668 \mathrm{~cd} / \mathrm{m}^{2}$ at $8.6 \mathrm{~V}$. Figure $1 \mathrm{~b}$ shows the electroluminescence (EL) spectra of the QLEDs according to increase the applied forward bias on the device. The peak position of the EL spectra was $536 \mathrm{~nm}$ regardless of the applied voltage. The full width at half maximum (FWHM) was $39 \mathrm{~nm}$, which is narrow enough to exhibit excellent color purity. The image of bright green light emitting QLEDs is shown in the inset of Fig. 1b. The interfacial electronic structure of QLEDs was measured using UPS, and energy level diagram is shown in Fig. 1c. The work functions of ITO and $\mathrm{Al}$, and the valence band maximum (VBM) of $\mathrm{V}_{2} \mathrm{O}_{5}, \mathrm{TFB}$, QDs, and $\mathrm{ZnO}$ were measured by preparing multilayer films of ITO, ITO/ $\mathrm{V}_{2} \mathrm{O}_{5}, \mathrm{ITO} / \mathrm{V}_{2} \mathrm{O}_{5} / \mathrm{TFB}, \mathrm{ITO} / \mathrm{V}_{2} \mathrm{O}_{5} / \mathrm{TFB} / \mathrm{QDs}$, $\mathrm{ITO} / \mathrm{V}_{2} \mathrm{O}_{5} / \mathrm{TFB} / \mathrm{QDs} / \mathrm{ZnO}$, and ITO/ $\mathrm{V}_{2} \mathrm{O}_{5} / \mathrm{TFB} / \mathrm{QDs} / \mathrm{ZnO} / \mathrm{Al}$, respectively. The secondary electron cutoff (SEC) and the highest occupied energy state molecular orbital (HOMO) values of each thin films was obtained from the spectra as shown in Figure S1. The work functions of ITO and Al were measured as $4.68 \mathrm{eV}$ and $3.59 \mathrm{eV}$, respectively. The $\mathrm{VBM}$ of $\mathrm{V}_{2} \mathrm{O}_{5}(1 \mathrm{wt} \%)$ was measured as $2.63 \mathrm{eV}$ below the Fermi energy $\left(\mathrm{E}_{\mathrm{F}}\right)$, while the distance between the vacuum level $\left(\mathrm{E}_{\mathrm{V}}\right)$ and the $\mathrm{E}_{\mathrm{F}}$ was obtained as $5.27 \mathrm{eV}$. As shown in the inset of Figure $\mathrm{S} 1$, the gap state was observed $0.65 \mathrm{eV}$ below the $\mathrm{E}_{\mathrm{F}}$ in $\mathrm{V}_{2} \mathrm{O}_{5}$ HIL. The gap state can promote the injection of hole carriers form ITO into $\mathrm{TFB}^{25}$. The optical band gap and the conduction band minimum (CBM) of $\mathrm{V}_{2} \mathrm{O}_{5} \mathrm{HIL}$ were calculated from the Tauc's plots of absorbance spectrum of $\mathrm{V}_{2} \mathrm{O}_{5}$ as shown in Figure $\mathrm{S} 2$. The CBM of $\mathrm{V}_{2} \mathrm{O}_{5} \mathrm{HIL}$ was located $0.55 \mathrm{eV}$ above the $\mathrm{E}_{\mathrm{F}}$. The VBM and the $\mathrm{CBM}$ of TFB, QDs, and $\mathrm{ZnO}$ were obtained using the same process and summarized in the Fig. 1c. Through the gap state of $\mathrm{V}_{2} \mathrm{O}_{5}$ and the $\mathrm{CBM}$ of $\mathrm{ZnO}$, hole and electron carriers can inject well into the emissive layer of QDs at the forward bias condition to emit a bright light.

A bright light could be emitted from the QLEDs with an appropriate interfacial electronic structure for the efficient charge injection and transport. However, the off-current of the QLEDs is too high in reverse bias to be used as a photodetector. The thickness of $\sim 1 \mathrm{wt} \% \mathrm{~V}_{2} \mathrm{O}_{5}$ HIL was $\sim 6 \mathrm{~nm}^{26}$. Also the thickness of $3 \mathrm{wt} \% \mathrm{~V}_{2} \mathrm{O}_{5}$ and $5 \mathrm{wt} \% \mathrm{~V}_{2} \mathrm{O}_{5}$ was estimated using the cross-sectional TEM images as shown in Figure S3. The thickness of $3 \mathrm{wt} \%$ $\mathrm{V}_{2} \mathrm{O}_{5}$ was $\sim 14.4 \mathrm{~nm}$, while the thickness of $5 \mathrm{wt} \% \mathrm{~V}_{2} \mathrm{O}_{5}$ was $\sim 25.9 \mathrm{~nm}$. Therefore, the thickness of $\mathrm{V}_{2} \mathrm{O}_{5}$ HIL depends on the concentration of the vanadium precursor, and affects to the charge transfer. The thickness of the $\mathrm{V}_{2} \mathrm{O}_{5} \mathrm{HIL}$ was controlled to increase the photoresponsivity by lowering the leakage current. QLEDs fabricated with the higher concentration ( $5 \mathrm{wt} \%$ ) of $\mathrm{V}_{2} \mathrm{O}_{5}$ solution exhibits less currents at the reverse bias than the device fabricated with the lower concentration of $\mathrm{V}_{2} \mathrm{O}_{5}$ solution, as shown in Figure S4. Therefore, the device can be optimized to be applicable for a photosensor by controlling the $\mathrm{V}_{2} \mathrm{O}_{5} \mathrm{HIL}$ and reducing the off current at the reverse bias. The interfacial electronic structures of ITO/ $\mathrm{V}_{2} \mathrm{O}_{5}(1,3,5 \mathrm{wt} \%) / \mathrm{TFB} / \mathrm{QDs}$ were measured using UPS. Figure 2a shows the UPS spectra of bare ITO glass, $\mathrm{V}_{2} \mathrm{O}_{5}$ on ITO glass spin-coated with different concentrations of $\mathrm{V}_{2} \mathrm{O}_{5}$ solution. The work function of ITO was $4.66 \mathrm{eV}$, which can be obtained from the SEC region spectrum. According to increase the thickness of $\mathrm{V}_{2} \mathrm{O}_{5} \mathrm{HIL}$, the HOMO level shifts from 2.63 to $2.58 \mathrm{eV}$, and gap state energy level shifts from 0.65 to $0.6 \mathrm{eV}$ from the Fermi level, while the density of state (DOS) of the $\mathrm{V}_{2} \mathrm{O}_{5}$ thin film depends on the precursor concentration as shown in the HOMO region and near the $\mathrm{E}_{\mathrm{F}}$ (Inset of Fig. 2a). Since the gap state plays an important role in the hole injection and transport through the $\mathrm{V}_{2} \mathrm{O}_{5}$ HIL, the shift of gap state energy level is an important factor in the hole transfer mechanism. Figure $2 \mathrm{~b}$ summarizes the SEC region and valence region spectra in Fig. $2 \mathrm{a}$, and shows the interfacial energy level according to the different concentration of $\mathrm{V}_{2} \mathrm{O}_{5}$. The HOMO and gap state levels of the $\mathrm{V}_{2} \mathrm{O}_{5} \mathrm{HIL}$ get closer to the $\mathrm{E}_{\mathrm{F}}$ according to increase the concentration of $\mathrm{V}_{2} \mathrm{O}_{5}$ solution. In QLEDs mode, $0.7 \mathrm{eV}$ offset of $\mathrm{V}_{2} \mathrm{O}_{5}(1 \mathrm{wt} \%)$ is a low offset energy barrier from $\mathrm{V}_{2} \mathrm{O}_{5}$ to TFB compared to the $0.75 \mathrm{eV}$ offset of $\mathrm{V}_{2} \mathrm{O}_{5}$ (5 wt\%), making hole relatively easily injected. The low offset between the gap state level of HIL and the HOMO level of HTL can improve the EL performance. The $\mathrm{V}_{2} \mathrm{O}_{5}(1 \mathrm{wt} \%)$ HIL showed the best EL characteristics due to the improvement of charge balance. The $\mathrm{V}_{2} \mathrm{O}_{5}$ ( $5 \mathrm{wt} \%$ ) induces hole accumulation due to the high energy barrier, which causes a weakening of the current injection. Figure S5 shows the EL performances of the device with different vanadium concentrations. The $3 \mathrm{wt} \%$ 
(a)

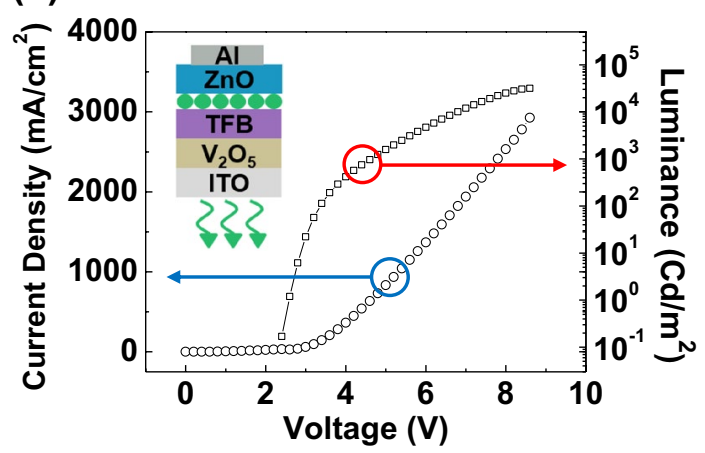

(b)

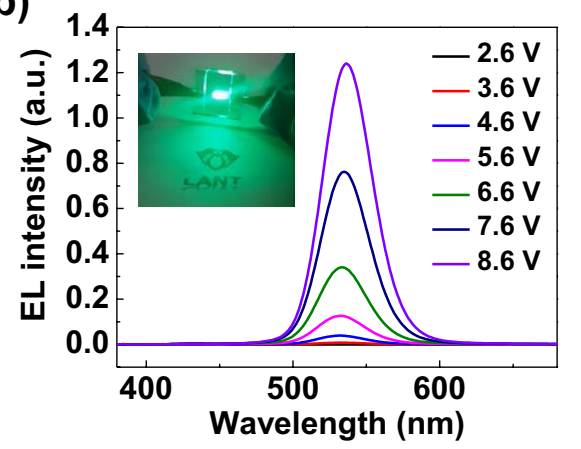

(c)

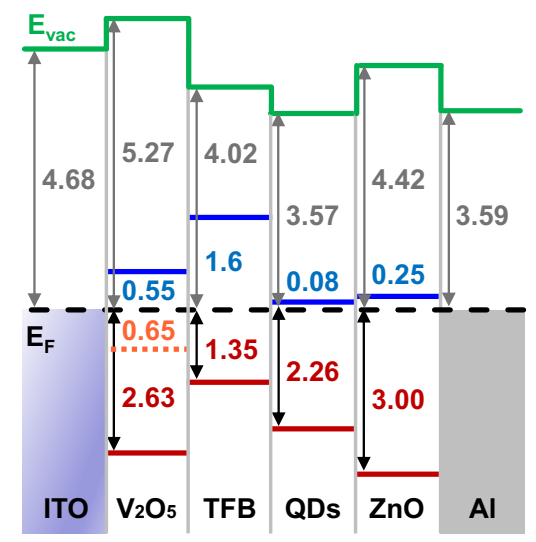

Figure 1. (a) Current density and luminance versus applied voltage curves of QLEDs. (J-L-V) Inset shows a schematic illustration of the QLEDs under forward bias for the light emission. (b) Electroluminescence spectra of QLEDs. Inset shows the light emitting QLEDs. (c) Energy level diagram of the QLEDs measured from UPS. The concentration of $\mathrm{V}_{2} \mathrm{O}_{5}$ was $1 \mathrm{wt} \%$.

and $5 \mathrm{wt} \% \mathrm{~V}_{2} \mathrm{O}_{5}$ QLEDs exhibited maximum luminance of $18,110 \mathrm{~cd} / \mathrm{m}^{2}$ and $14,127 \mathrm{~cd} / \mathrm{m}^{2}$, respectively. As the vanadium precursor concentration increase, the current density decrease. The EL specta have the peak position at $536 \mathrm{~nm}$. Compared to the current efficiency for each concentration of $\mathrm{V}_{2} \mathrm{O}_{5}$, the maximum current efficiency of $1 \mathrm{wt} \% \mathrm{~V}_{2} \mathrm{O}_{5}$ is $1.09 \mathrm{~cd} / \mathrm{A}$. In PD mode, hole that is easily moved to high energy state are transferred regardless of the gap state of $\mathrm{V}_{2} \mathrm{O}_{5}$ depending on the concentration. However, $\mathrm{V}_{2} \mathrm{O}_{5}(1 \mathrm{wt} \%)$ indicates a leakage current that is too large compared to the generated photocurrent, so that no photoresponsivity occurs. On the other hand, the $\mathrm{V}_{2} \mathrm{O}_{5}(5 \mathrm{wt} \%) \mathrm{HIL}$ decreases the leakage current as the thickness of HIL increases, to improve the photodetector.

XPS measurements have been performed on each $\mathrm{V}_{2} \mathrm{O}_{5}$ thin film, fabricated with different concentration of the solution, to analyze the origin of the different DOS of the gap state energy level. Figure 3 shows the XPS core level spectra of vanadium (V $2 p)$ and oxygen $(\mathrm{O} 1 s)$ to analyze the composition of the $\mathrm{V}_{2} \mathrm{O}_{5}$ HIL. The peak positions for $\mathrm{V} 2 p_{1 / 2}, \mathrm{~V} 2 p_{3 / 2}$, and $\mathrm{O} 1 s$ were $524.3,516.9$ and $530 \mathrm{eV}$, respectively. There was no significant difference in the $\mathrm{V} 2 p_{1 / 2}$ peak. However, asymmetric peak was observed in the low binding energy portion of the $\mathrm{V} 2 p_{3 / 2}$ peak, which indicates the presence of various oxidation states of $\mathrm{V}_{2} \mathrm{O}_{5}$. The spectra of $\mathrm{V} 2 p_{3 / 2}$ oxidation state can be separated to $\mathrm{V}^{4+}(515.9 \mathrm{eV})$ and $\mathrm{V}^{5+}(517 \mathrm{eV})$ through the Lorentzian-Gaussian fitting, as shown in Fig. 3a-c. The $\mathrm{V}^{5+}$ state at the higher binding energy indicates $\mathrm{V}_{2} \mathrm{O}_{5}$, while the $\mathrm{V}^{4+}$ state corresponds to $\mathrm{VO}_{2}$, which indicates the gap state. The amount of $\mathrm{VO}_{2}$ increases from 26.9 to $31.1 \%$ according to increase the concentration of $\mathrm{V}_{2} \mathrm{O}_{5}$ 
(a)

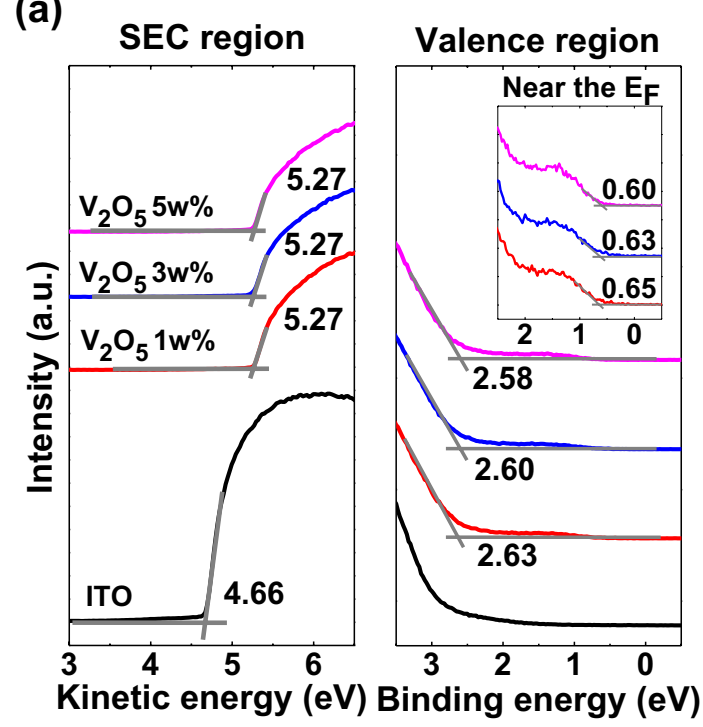

(b)

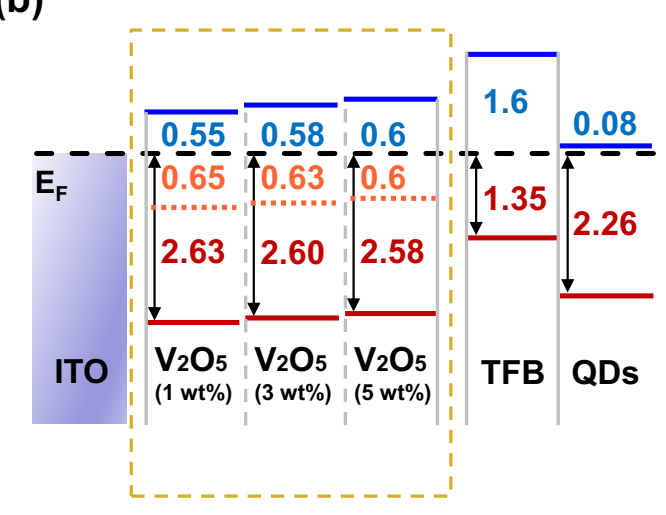

Figure 2. (a) UPS spectra of ITO and various concentration $\mathrm{V}_{2} \mathrm{O}_{5}$ films on ITO at the secondary cutoff and $\mathrm{E}_{\mathrm{F}}$ regions. To clarify the gap state, inset shows near the $\mathrm{E}_{\mathrm{F}}$ (b) Energy level diagram of the hole injection region of the QLEDs. Inside the dotted square, gap states and HOMO levels of different concentration $\mathrm{V}_{2} \mathrm{O}_{5}$ films on ITO are shown.

solution from 1 to $5 \mathrm{wt} \%$. Therefore, it can be suggested that rich $\mathrm{V}^{4+}$ states of $\mathrm{V}_{2} \mathrm{O}_{5}$ shows a gap state closer to $\mathrm{E}_{\mathrm{F}}$ based on the UPS and XPS measurements. Besides, the $\mathrm{O} 1 s$ peak can be separated by $\mathrm{V}^{4+}(531.2 \mathrm{eV})$ and $\mathrm{V}^{5+}$ $(530 \mathrm{eV})$ by Lorentzian-Gaussian fitting, as well, as shown in Fig. $3 \mathrm{~d}-\mathrm{f}$. The amount of $\mathrm{V}^{4+}$ state increases from 10.1 to $12.1 \%$ according to increase the concentration of $\mathrm{V}_{2} \mathrm{O}_{5}$ solution from 1 to $5 \mathrm{wt} \%$. Therefore, the result indicates that $\mathrm{VO}_{2}$ leads the increase of DOS of the gap state, and affects to the hole transfer behavior.

To evaluate the photodetection behavior of the dual-functional QLEDs, a device was prepared with the $5 \mathrm{wt} \%$ $\mathrm{V}_{2} \mathrm{O}_{5}$ solution as shown in the inset of the Fig. 4a. Figure 4a shows the I-V characteristics of the dual-functional QLEDs with and without the illumination of light $(\lambda=405,450,520,635 \mathrm{~nm})$. Since the band gap of QDs was $2.34 \mathrm{eV}$, it is hard to observe a photocurrent with the illumination of $635 \mathrm{~nm}$ wavelength light $(1.95 \mathrm{eV})$. Meanwhile, an increase of the photocurrent could be observed with the illumination of light $(\lambda=405,450,520 \mathrm{~nm})$ on the device at the reverse bias. The photon energy of the light $(\lambda=405,450,520 \mathrm{~nm})$ was high enough to excite carriers from the VBM to CBM of QDs. The device shows excellent photoresponsivity in light illumination over $520 \mathrm{~nm}(2.38 \mathrm{eV})$, because of band gap of the active layer CdSe/ZnS QDs, which has an absorbance peak around $520 \mathrm{~nm}$, as shown in Figure S6. As the reverse bias voltage increases, the increase of the photocurrent was observed due to the strong external electric field to collect the charges. The photoresponsivity of dual-functional QLEDs at the photodetection mode can be calculated using the following equation.

$$
\mathrm{R}=\frac{\mathrm{I}_{\text {light }}-\mathrm{I}_{\text {dark }}}{\mathrm{PA}}
$$

where $I_{\text {light }}$ is the photocurrent under various wavelengths of illumination, $I_{\text {dark }}$ is the dark current, $P$ is the incident light power and $A$ is the illuminated area of the device. The photoresponsivity was calculated and shown in Table S1. In our previously study, we reported a photodiode suing QDs and oxide semiconductor with the 
(a)

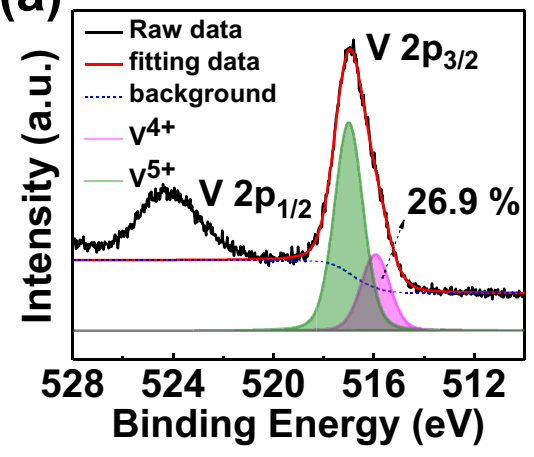

(d)

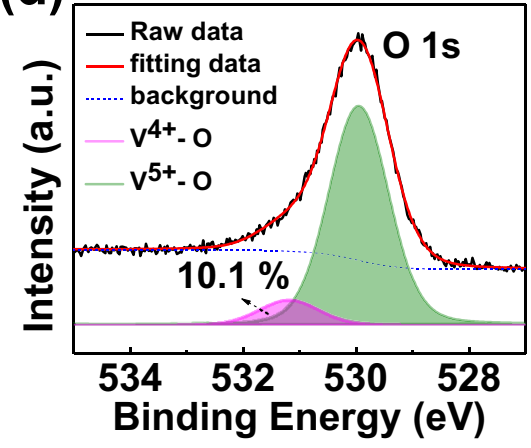

(b)

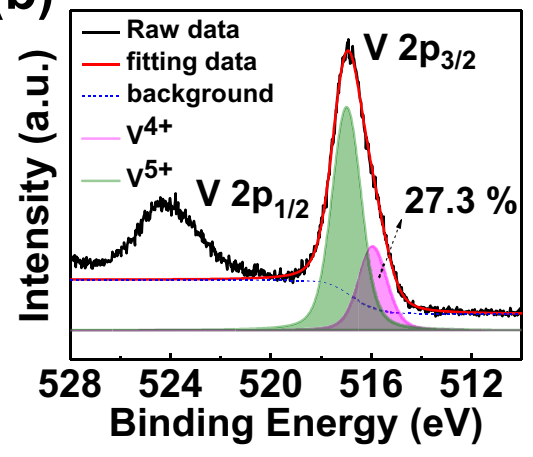

(e)

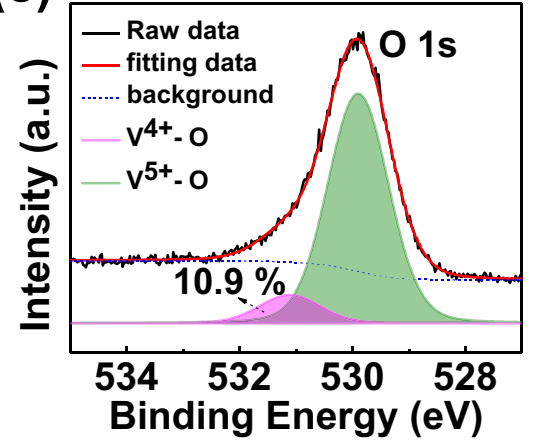

(c)

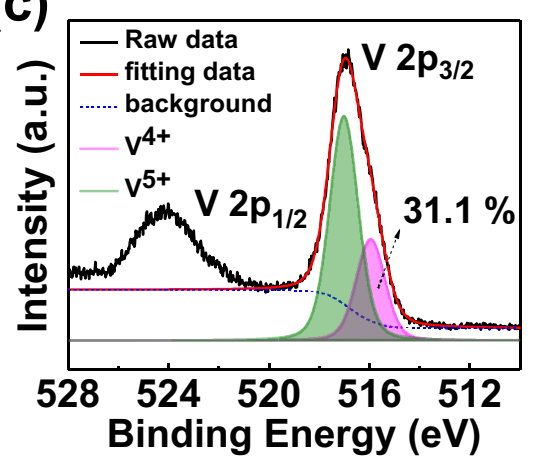

(f)

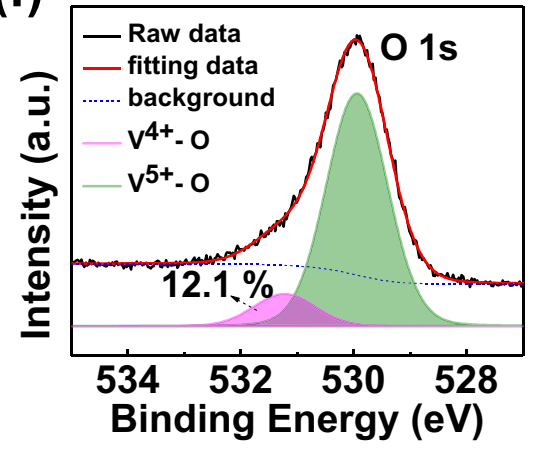

Figure 3. Measured V $2 p_{3 / 2}$ and $\mathrm{O} 1 s$ core level spectra of (a), (d) $1 \mathrm{wt} \% \mathrm{~V}_{2} \mathrm{O}_{5}$ film on ITO, (b), (e) 3 wt $\% \mathrm{~V}_{2} \mathrm{O}_{5}$ film on ITO, and (c), (f) $5 \mathrm{wt} \% \mathrm{~V}_{2} \mathrm{O}_{5}$ film on ITO. In the $\mathrm{V} 2 p$ core-level spectra, the ratio of $\mathrm{V}^{4+}$ and $\mathrm{V}^{5+}$ are shown, while the ratio of oxygen binding ratio with $\mathrm{V}^{4+}$ and $\mathrm{V}^{5+}$ is shown in $\mathrm{O} 1 s$ core-level spectra.

photoresponsivity of $0.09 \mathrm{~A} / \mathrm{W}^{16}$. In this study, the dual-functional devices with $\mathrm{V}_{2} \mathrm{O}_{5}$ HIL have a photoresponsivity of $0.0076 \mathrm{~A} / \mathrm{W}$, which is similar to our previous study. Higher reverse bias improved the generation of the photo-excited carriers. The photoresponses of the dual-functional QLEDs with the periodic light illumination of various wavelengths of light and reverse biases are shown in Figure S7. Figure $4 \mathrm{~b}$ shows a normalized, single rising and falling cycle measured with a $520 \mathrm{~nm}$ light illumination with $-2 \mathrm{~V}$. The response speed was measured in two parts. When the light illumination was turned on and off, the voltage was defined as the rising time $\left(\tau_{\mathrm{r}}\right)$ and falling time $\left(\tau_{\mathrm{f}}\right)$, respectively, at time intervals between 10 and $90 \%$ of the output of the normalized voltage. The $\tau_{\mathrm{r}}$ and $\tau_{\mathrm{f}}$ are determined as 2.4 and $13.6 \mathrm{~ms}$, respectively. The voltage-time $(\mathrm{V}-\mathrm{T})$ characteristic of the device with various frequencies of input light signal is shown in Fig. 4c. A periodic photomodulation was clearly observed with the periodic light signal from 10 to $100 \mathrm{~Hz}$. This demonstrates that the device can operate in a frequency range that is similar to the human eye. Also, the speed of this reaction indicates that the device is capable of detecting a frequency that are difficult for the human eye to detect in the on-off cycle of light illumination.

Time-resolved photoluminescence (TRPL) measurements using a time-correlated single-photon counting technique were performed to analyze charge decay dynamics as shown in Fig. 5a. A single layer of CdSe/ZnS QDs thin film on quartz and full dual-functional device were prepared for the measurements. The TRPL of the full device was measured at a forward bias of $3.8 \mathrm{~V}$, which gives a sufficiently bright light in the LED mode, and at a reverse bias of $-3.8 \mathrm{~V}$, which is a photodetection mode. To clarify the comparison of the device's charge transition mechanism, measurement at zero bias was performed as well, where the device does not work. During the measurement, the sample was excited using a $400 \mathrm{~nm}$ wavelength pulsed laser, and TRPL decay profiles were recorded with a probe at $520 \mathrm{~nm}$ wavelength. The PL decay dynamics of the CdSe/ZnS QDs monolayer and full device at various biases were significantly different as shown in Fig. 5a.

The average transient PL decay time $<\tau>$ is estimated by fitting the component exponential decay model.

$$
\begin{gathered}
\mathrm{D}(\mathrm{t}) \approx \sum_{\mathrm{i}=1,2, \ldots} \mathrm{a}_{\mathrm{i}} \exp \left(-\frac{\mathrm{t}}{\tau_{\mathrm{i}}}\right) \\
<\tau>=\frac{a_{1} \tau_{1}^{2}+a_{2} \tau_{2}^{2}+\cdots}{a_{1} r_{1}+a_{2} r_{2}+\cdots}
\end{gathered}
$$

where $a_{i}=1,2, \ldots$ is the weighting coefficient, and $\tau_{i}=1,2, \ldots$ is the PL decay characteristic times. Here, we only use up to $i=2$ of the measured values for reasonable calculation (Table 1 ). The decay curve is applied with a biexponential $(\mathrm{i}=1,2)$ that includes non- radiative decay $(\mathrm{i}=1)$ and radiative decay $(\mathrm{i}=2)$ values. Radiative decay occurs when photons are absorbed, whereas non-radiative decay occurs due to other factors such as quenching 
(a)

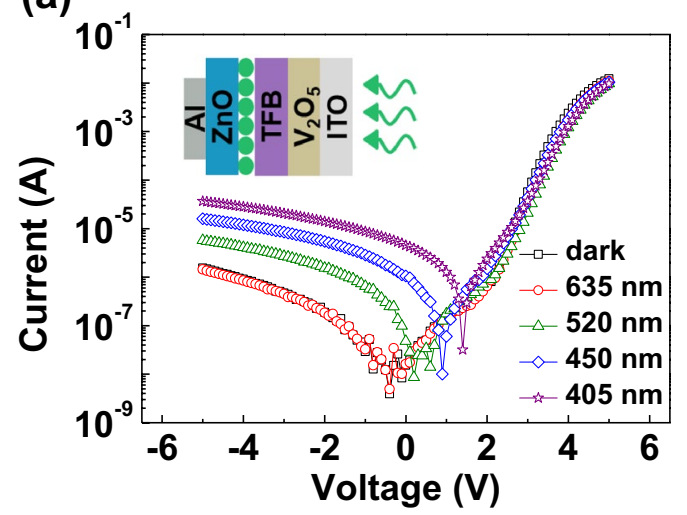

(b)

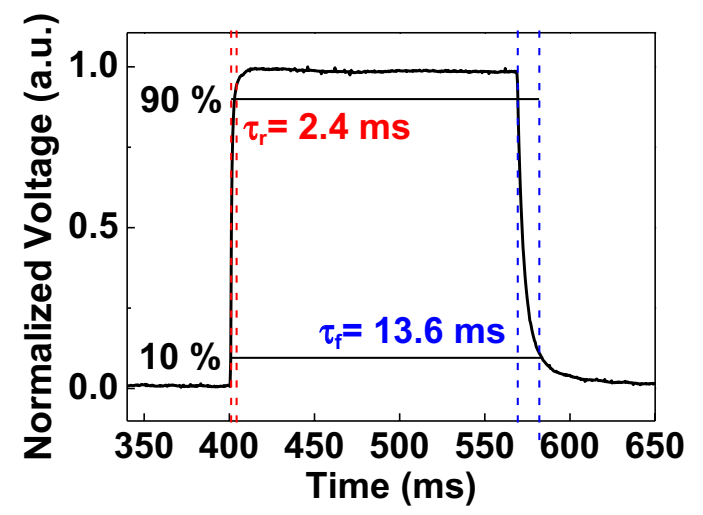

(c)

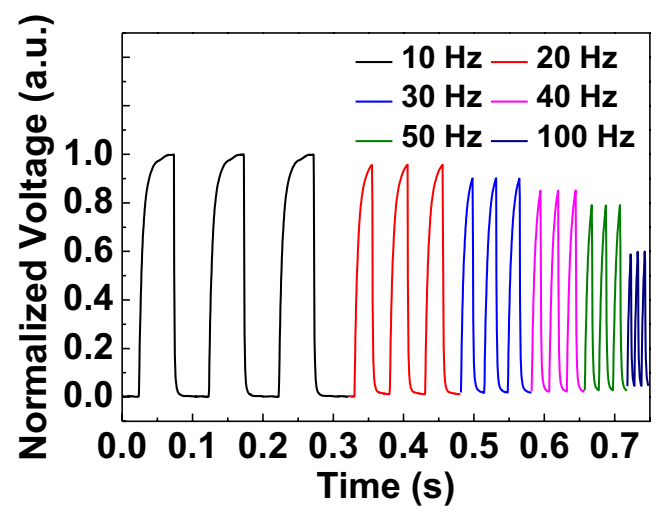

Figure 4. (a) Transfer curves of the device in a dark state and with the illumination of various wavelengths light. Inset shows a schematic illustration of the QLEDs with $5 \mathrm{wt} \% \mathrm{~V}_{2} \mathrm{O}_{5}$ for the light detecting process. (b) Photo response characteristics of the device. Rising and falling time was defined as the interval between 10 and $90 \%$ of the signal. (c) Normalized photo responses according to the different speed of turn on and off the $520 \mathrm{~nm}$ wavelength light signal.

and vibration that do not involve absorption. The PL decay of the full device is faster than that of the CdSe/ZnS QDs film. Therefore, it can be said that the exciton by the light in the QDs of the full device was transferred easily to the other layers. Compared to the PL decay of the full device with $0 \mathrm{~V}$, the PL decay of the device with the forward bias is slower. This means efficient recombination due to reduced exciton transition. And the PL decay with the reverse bias $(-3.8 \mathrm{~V})$ is the fastest, that means the photon energy can transfer to the other charge transport layer efficiently for the light detecting of dual-functional QLEDs. The charge transfer rate constant $\kappa_{c t}$ can be estimated from the decay time using the following equation,

$$
\kappa_{c t}=\frac{1}{\tau_{1}}+\frac{1}{\tau_{2}}
$$


(a)

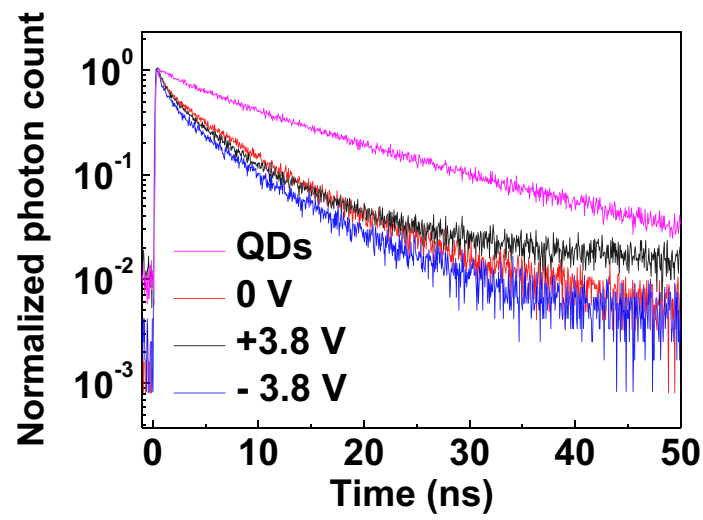

Figure 5. (a) Time-resolved photoluminescence decay results of QDs on quartz and full devices with zero bias, light-emitting mode $(+3.8 \mathrm{~V})$ and light-detecting mode $(-3.8 \mathrm{~V})$, respectively.

\begin{tabular}{|l|l|l|l|l|l|}
\hline & $\boldsymbol{a}_{\mathbf{1}}$ & $\boldsymbol{t}_{\mathbf{1}}(\mathbf{n s})$ & $\boldsymbol{a}_{\mathbf{2}}$ & $\boldsymbol{t}_{\mathbf{2}}(\mathbf{n s})$ & Average lifetime $<\boldsymbol{\tau}>(\mathbf{n s})$ \\
\hline $\mathrm{QDs}$ & 0.422 & 5.710 & 0.558 & 17.072 & 14.692 \\
\hline $0 \mathrm{~V}$ & 0.422 & 1.020 & 0.578 & 6.743 & 6.173 \\
\hline$+3.8 \mathrm{~V}$ & 0.768 & 2.138 & 0.232 & 13.140 & 9.288 \\
\hline$-3.8 \mathrm{~V}$ & 0.571 & 0.957 & 0.429 & 6.576 & 5.664 \\
\hline
\end{tabular}

Table 1. Summary of the average lifetime of charge carriers from the QDs on quartz and full devices with zero bias, light-emitting mode $(+3.8 \mathrm{~V})$ and light-detecting mode $(-3.8 \mathrm{~V})$.

\begin{tabular}{|l|l|l|l|}
\hline & $\mathbf{1} / \boldsymbol{t}_{\mathbf{1}}\left(\mathbf{n s}^{-\mathbf{1}}\right)$ & $\mathbf{1} / \mathbf{t}_{\mathbf{2}}\left(\mathbf{n s}^{-\mathbf{1}}\right)$ & Transition rate $<\boldsymbol{t}^{-\mathbf{1}}>\left(\mathbf{n s}^{-\mathbf{1}}\right)$ \\
\hline QDs & 0.175 & 0.058 & 0.233 \\
\hline $0 \mathrm{~V}$ & 0.980 & 0.148 & 1.128 \\
\hline$+3.8 \mathrm{~V}$ & 0.467 & 0.076 & 0.543 \\
\hline$-3.8 \mathrm{~V}$ & 1.044 & 0.152 & 1.197 \\
\hline
\end{tabular}

Table 2. Summary of the charge transition rate estimated from the decay time of the QDs on quartz and full devices with zero bias, light-emitting mode $(+3.8 \mathrm{~V})$ and light-detecting mode $(-3.8 \mathrm{~V})$.

where $\tau_{1}$ and $\tau_{2}$ are the decay characteristic times. Table 2 shows that the electron transition rate is increased at full device compared to QDs on quartz. It is attributed to the conduction level of the other surrounding layers helps to accelerate the transfer of excited charge from QDs by reducing the energy level offset. Besides, it shows a very different electron transition rate results of $0.543 \mathrm{~ns}^{-1}$ at $+3.8 \mathrm{~V}$ and $1.197 \mathrm{~ns}^{-1}$ at $-3.8 \mathrm{~V}$, respectively. In QLEDs mode, excited photons are recombined while not being transferred to the interfacial layer by forward bias, resulting in a low transition rate. In contrast, PD mode excited photons are accelerated to the electrode by reverse bias with the built-in electric field in the surrounding layers. This indicates a high transition rate by inhibiting recombination of excitons.

A circuit, which can detect a visible light and generate a visible light through two identical dual-functional QLEDs was demonstrated as shown in Fig. 6a. The QLEDs and photodiodes used $5 \mathrm{wt} \% \mathrm{~V}_{2} \mathrm{O}_{5}$ of dual-functional diodes. The first device (PD) was reverse biased to detect the input $520 \mathrm{~nm}$ wavelength light signal, and generated an electrical signal to drive the amplification circuit. Then, the second device (QLEDs), which is forward biased, can emitted a $520 \mathrm{~nm}$ wavelength light from the amplified electrical signal, which was generated from the PD. For the amplification of the photocurrent, operation amplifier (Op amp) circuit was used. Figure $6 \mathrm{~b}$ shows the periodic photoresponses, measured at the position of (ii), just before input the second device. The periodic input laser signal is shown as a black line in the Fig. $6 \mathrm{~b}$. When a $520 \mathrm{~nm}$ wavelength laser light was used for the input signal, periodic photoresponses was clearly observed. However, it is hard to observe any photoresponses with the illumination of $635 \mathrm{~nm}$ wavelength light signal due to the band gap of QDs. Figure 6c shows the periodic emitting light signal from the QLEDs due to the input light signal at the position of (i) on the circuit. Periodic light emitting modulation was clearly observed as shown in the Fig. 6c. Therefore, we can generate a visible light 
(a)

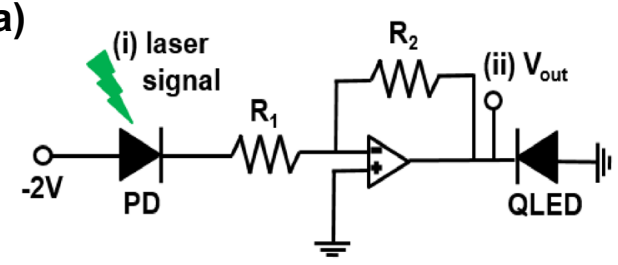

(b)

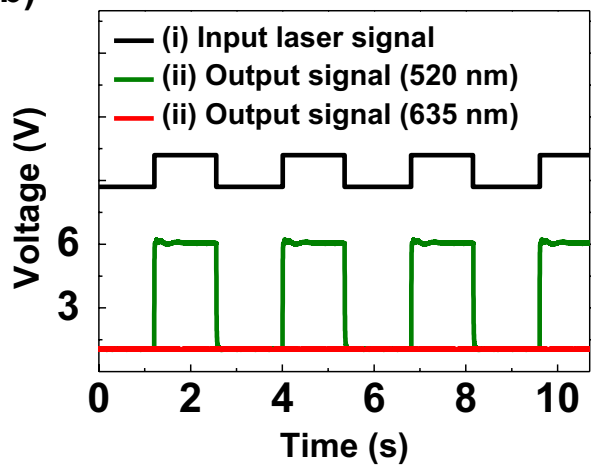

(c)

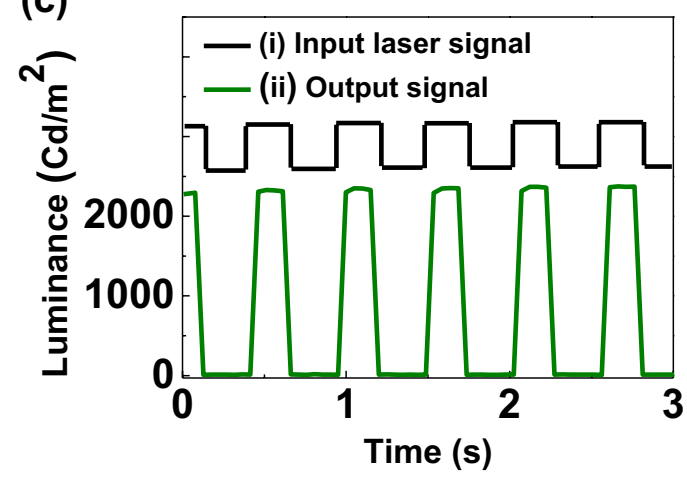

Figure 6. (a) Circuit diagram that used two dual-functional QLEDs. Input laser signal enables to produce enough electrical signal from the first device (PD) to turn-on the second device (QLEDs) for the light emission. (b) Periodic photoresponses of the PD according to the 520 and $635 \mathrm{~nm}$ wavelength light signal measured at (ii) $\mathrm{V}_{\text {out }}$ of the circuit diagram. (c) Luminescence characteristics of the QLEDs according to the periodic input laser signal $(\lambda=520 \mathrm{~nm})$ into the PD.

emission from the dual-functional QLEDs by an electrical signal from the visible light signal as shown in the Figure S8, which was generated from the identical device with the reverse bias.

Figure 7 shows that the light signal from the QLEDs can generate an electrical signal via the other dualfunctional device, which was used as a light detection mode. Figure 7a shows the circuit diagram consists of two functional diodes at position. Here in, to detect with high photoresponsivity from a photodiode, the circuit was optimized using QLEDs fabricated with $1 \mathrm{wt} \% \mathrm{~V}_{2} \mathrm{O}_{5}$. And the photodetector used a $5 \mathrm{wt} \% \mathrm{~V}_{2} \mathrm{O}_{5}$. A periodic input electrical signal was applied to the first QLEDs to generate a periodic light signal of $520 \mathrm{~nm}$ wavelength. The periodic light emitting signal is shown as a green line in Fig. 7b. The periodic light signal was illuminated on the second dual-functional QLEDs to generate an electrical signal. By amplifying the electrical signal using OP amp circuit, a periodic electrical signal was clearly observed at the position of (ii) in the circuit. Inset shows the image of turn-on state and turn-off state of the QLEDs in Fig. 7b. Therefore, dual-functional QLEDs can be used simultaneously as a light emitter and receiver with an appropriate applied bias and enable the developments of efficient visible communications.

\section{Conclusions}

We have fabricated dual-functional QLEDs using a solution processable $\mathrm{V}_{2} \mathrm{O}_{5} \mathrm{HIL}$. The device shows a selectable functionalities of photo-detection and light-emitting via an optimization of $\mathrm{V}_{2} \mathrm{O}_{5}$ (5 wt\%) HIL with an appropriate applying voltage. From the measurement of XPS and UPS, we found a gap state in $\mathrm{V}_{2} \mathrm{O}_{5} \mathrm{HIL}$, and the gap state level moved closer to the $\mathrm{E}_{\mathrm{F}}$ and the DOS of gap state increased, according to increase the concentration of $\mathrm{V}_{2} \mathrm{O}_{5}$ precursor. The change of gap state enables to fabricate a dual-functional QLEDs. The device emitted a 
(a)

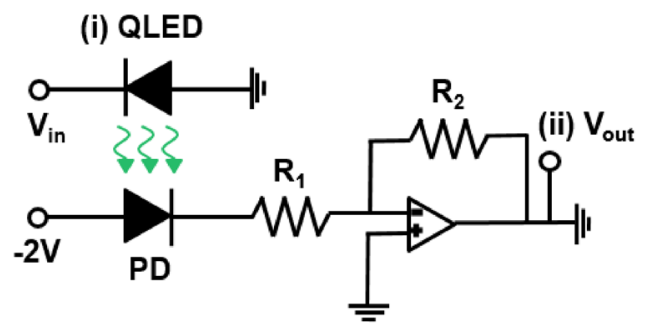

(b)

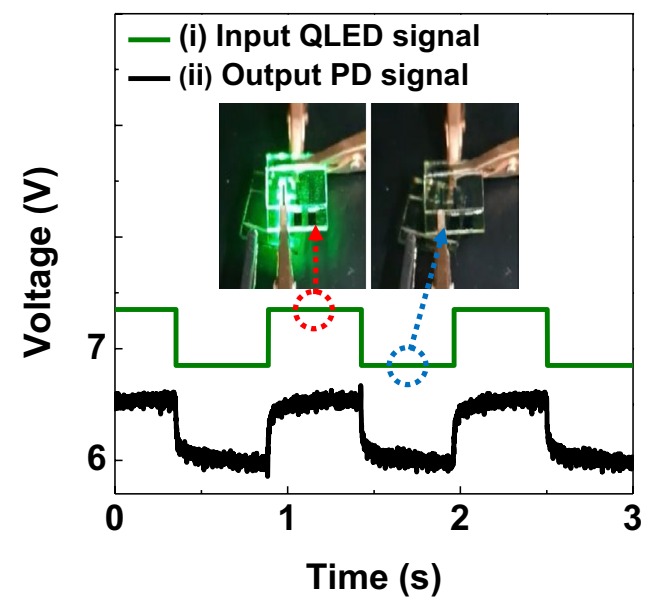

Figure 7. (a) Circuit diagram to generate an electrical signal using PD from the light emission of QLEDs. (b) Periodic output electrical signal of PD measured at (ii) $V_{\text {out }}$ from the input light generated from the (i) dualfunctional QLEDs. Inset shows the image of turn-on state QLEDs to generate electrical signal from the PD and turn-off state QLEDs to turn-off the PD.

bright green light at the wavelength of $520 \mathrm{~nm}$, and with the maximum luminance of $31,668 \mathrm{~cd} / \mathrm{m}^{2}$ in a forward bias of $8.6 \mathrm{~V}$. Meanwhile, the device could operate as a photodetector in a reverse bias condition. The device was perfectly turned off in a reverse bias with $5 \mathrm{wt} \% \mathrm{~V}_{2} \mathrm{O}_{5} \mathrm{HIL}$, while an increase of photocurrent was observed during the illumination of a visible-light on the device. Therefore, dual-functional QLEDs can be used simultaneously as a light emitter and receiver with an appropriate applied bias. The result suggests that QLEDs can be used as a photosensor and as a light-emitting diode for the optoelectronics for the next-generation IoT and visible communications.

\section{Methods}

Materials. Patterned indium-tin-oxide (ITO) glass was purchased from AMG tech, and aluminum (Al) was purchased from Taewon scientific. Vanadium (V) triisopropoxide oxide and poly [(9,9-dioctylfluorenyl-2,7diyl)-co-(4,4'-(4-s-butylphenyl) diphenylamine)]] (TFB) was purchased from Alfa Aesar and Lumtec, respectively. CdSe/ZnS QDs were purchased from Uniam, and $\mathrm{ZnO}$ was purchased from Avantama. p-xylene was purchased from Sigma Aldrich.

Synthesis of $\mathbf{V}_{2} \mathrm{O}_{5}$ and TFB. Various concentrations $(1,3$, and $5 \mathrm{wt} \%)$ of the vanadium oxide solution were synthesized by adding vanadium $(\mathrm{V})$ triisopropoxide oxide $(0.05,0.16$, and $0.28 \mathrm{ml})$ into isopropyl alcohol $(7 \mathrm{ml})$, respectively. The solution was mixed for $10 \mathrm{~min}$ at $600 \mathrm{rpm}$ using a stirring bar. Then deionized water $(0.1 \mathrm{ml})$ was added, followed by mixing for $50 \mathrm{~min}$ to activate the hydrolysis reaction. $1 \mathrm{wt} \%$ of TFB solution was prepared by mixing TFB $(0.0173 \mathrm{~g})$ into p-xylene $(99 \%, 2 \mathrm{ml})$. The TFB solution was stirred for $30 \mathrm{~min}$ at $600 \mathrm{rpm}$ with a hot plate temperature of $80^{\circ} \mathrm{C}$.

Fabrication of dual functional diode. Patterned ITO with a sheet resistance of $15 \Omega \mathrm{sq}^{-1}$ on a glass substrate was used as the anode. The ITO was rinsed with acetone, IPA and DI water in the order. The work function and the surface hydrophilicity of ITO were increased by using ultraviolet/ozone treatment. The $\mathrm{V}_{2} \mathrm{O}_{5}$ solution was spin-coated onto the ITO surface at $3000 \mathrm{rpm}$ for $1 \mathrm{~min}$. The coated $\mathrm{V}_{2} \mathrm{O}_{5}$ layer was annealed at $150{ }^{\circ} \mathrm{C}$ for $15 \mathrm{~min}$ and then kept at room temperature for $10 \mathrm{~min}$. TFB solution was spin-coated at $3000 \mathrm{rpm}$ for $30 \mathrm{~s}$ onto the $\mathrm{V}_{2} \mathrm{O}_{5}$ layer. The coated TFB layer was annealed at $180^{\circ} \mathrm{C}$ for $30 \mathrm{~min}$. The CdSe/ZnS QDs solution was spincoated at $1500 \mathrm{rpm}$ for $1 \mathrm{~min}$ onto the TFB layer. The coated CdSe/ZnS QDs layer was annealed at $180{ }^{\circ} \mathrm{C}$ for 
$30 \mathrm{~min}$. The $\mathrm{ZnO}$ solution was spin-coated at $2000 \mathrm{rpm}$ for $1 \mathrm{~min}$ onto the $\mathrm{CdSe} / \mathrm{ZnS}$ QDs layer. The coated $\mathrm{ZnO}$ layer was annealed at $180^{\circ} \mathrm{C}$ for $30 \mathrm{~min}$. Al cathode was deposited by using a thermal evaporator with a shadow mask. Finally, the device was encapsulated using a thin glass with an epoxy.

Characterization. The interfacial electronic structures and chemical states were measured using UPS and XPS with an ultra-high vacuum system $\left(1 \times 10^{-9}\right.$ Torr $)$. Photoelectron spectra were recorded using a KTRATOS AXIS NOVA system. He-I $(21.218 \mathrm{eV})$ source was used for the UPS measurements, and x-ray source for XPS measurement was $\mathrm{Al} \mathrm{Ka}(1486.6 \mathrm{eV})$. Energy resolutions were approximately $0.1 \mathrm{eV}$ and $1.0 \mathrm{eV}$ for UPS and XPS, respectively. No sample temperature control was attempted during the experiments. Current-voltageluminance (I-V-L) characteristics of QLEDs were measured using a conventional measurement system (M6100, McScience). Current-voltage (I-V) characteristics of photodiodes were measured by using a probe station and 4145B semiconductor parameter analyzer. The carrier transfer mechanism was analyzed via time-resolved photoluminescence (TRPL) measurement. The periodic optical response behavior were evaluated using a function generator and an oscilloscope.

Received: 30 July 2020; Accepted: 5 January 2021

Published online: 18 January 2021

\section{References}

1. Zanella, A., Bui, N., Castellani, A., Vangelista, L. \& Zorzi, M. Internet of things for smart cities. IEEE Internet Things J. 1, 22-32 (2014).

2. Ortiz, A. M., Hussein, D., Park, S., Han, S. N. \& Crespi, N. The cluster between internet of things and social networks: review and research challenges. IEEE Internet Things J. 1, 206-215 (2014).

3. Lutai, L., Kharchenko, V., Fedorenko, R. \& Fedorenko, M. Expert assessment of post accidence monitoring systems with multiversion structures. In 2018 IEEE 9th International Conference on Dependable Systems, Services and Technologies (DESSERT) (2018).

4. Leng, T. et al. Printed graphene/WS 2 battery-free wireless photosensor on papers. 2D Mater. 7, 024004 (2020).

5. Liao, T. S., Lin, H. N. \& Lee, L. J. Simplified and universal resistance response of gas sensor of IoT circuit platform. In 2019 IEEE International Instrumentation and Measurement Technology Conference (I2MTC) (2019).

6. Mendiratta, S., Dey, D. \& Rani Sona, D. Automatic car parking system with visual indicator along with IoT. In 2017 International conference on Microelectronic Devices, Circuits and Systems (ICMDCS) (2017).

7. Shin, H.-J., Kim, S.-J., Jeon, M.-H. \& Oh, C.-H. Development of automatic mold shot measurement and management system for smart factory. Int. J. Electr. Comput. Eng. (IJECE) 6, 3142 (2016).

8. Warmerdam, K., Pandharipande, A. \& Caicedo, D. Connectivity in IoT indoor lighting systems with visible light communications. In 2015 IEEE Online Conference on Green Communications (OnlineGreenComm) (IEEE, 2015).

9. Hamdaoui, N., Ben Elkamel, I., Mezni, A., Ajjel, R. \& Beji, L. Highly efficient, low cost, and stable self-powered UV photodetector based on $\mathrm{Co}^{2+}: \mathrm{ZnO} / \mathrm{Sn}$ diluted magnetic semiconductor nanoparticles. Ceram. Int. 45, 17729-17736 (2019).

10. Yoo, H. et al. High photosensitive indium-gallium-zinc oxide thin-film phototransistor with a selenium capping layer for visiblelight detection. ACS Appl. Mater. Interfaces 12, 10673-10680 (2020).

11. Avătămăniței, S. A., Căilean, A.-M., Done, A., Dimian, M. \& Prelipceanu, M. Noise resilient outdoor traffic light visible light communications system based on logarithmic transimpedance circuit: experimental demonstration of a $50 \mathrm{~m}$ reliable link in direct sun exposure. Sensors 20, 909 (2020).

12. Calvanese Strinati, E. et al. 6G: the next frontier: from holographic messaging to artificial intelligence using subterahertz and visible light communication. IEEE Veh. Technol. Mag. 14, 42-50 (2019).

13. Ren, B. et al. Multifunctional optoelectronic devices: multifunctional optoelectronic device based on an asymmetric active layer structure. Adv. Funct. Mater. 29, 1970114 (2019).

14. Li, N., Lau, Y. S., Miao, Y. \& Zhu, F. Electroluminescence and photo-response of inorganic halide perovskite bi-functional diodes. Nanophotonics 7, 1981-1988 (2018).

15. Song, Z. et al. All-inorganic perovskite $\mathrm{CsPbBr}$ 3-based self-powered light-emitting photodetectors with $\mathrm{ZnO}$ hollow balls as an ultraviolet response center. J. Mater. Chem. C 6, 5113-5121 (2018).

16. Jeong, S. et al. High-speed colloidal quantum dot photodiodes via accelerating charge separation at metal-oxide interface. Small 15, 1900008 (2019).

17. Yu, H. et al. Solution-processed copper oxide interlayers for broadband PbS quantum-dot photodiodes. J. Mater. Chem. C 4, 11205-11211 (2016).

18. Mo, H. et al. Two-dimensional alloying molybdenum tin disulfide monolayers with fast photoresponse. ACS Appl. Mater. Interfaces 11, 39077-39087 (2019).

19. Dai, X., Deng, Y., Peng, X. \& Jin, Y. Quantum-dot light-emitting diodes for large-area displays: towards the dawn of commercialization. Adv. Mater. 29, 1607022 (2017).

20. Choi, M. K., Yang, J., Hyeon, T. \& Kim, D.-H. Flexible quantum dot light-emitting diodes for next-generation displays. npj Flex. Electron. 2, 1-14 (2018).

21. Litvin, A. P. et al. Colloidal quantum dots for optoelectronics. J. Mater. Chem. A 5, 13252-13275 (2017).

22. García de Arquer, F. P., Armin, A., Meredith, P. \& Sargent, E. H. Solution-processed semiconductors for next-generation photodetectors. Nat. Rev. Mater. 2, 1-17 (2017).

23. Shirasaki, Y., Supran, G. J., Bawendi, M. G. \& Bulović, V. Emergence of colloidal quantum-dot light-emitting technologies. Nat. Photonics 7, 13-23 (2012).

24. Oh, N. et al. Double-heterojunction nanorod light-responsive LEDs for display applications. Science 355, 616-619 (2017).

25. Lee, S. M., Shin, D., Cho, N.-K., Yi, Y. \& Kang, S. J. A solution-processable inorganic hole injection layer that improves the performance of quantum-dot light-emitting diodes. Curr. Appl. Phys. 17, 442-447 (2017).

26. Heo, S. B. et al. Interfacial electronic structure between a W-doped $\operatorname{In}_{2} \mathrm{O}_{3}$ transparent electrode and a $\mathrm{V}_{2} \mathrm{O}_{5}$ hole injection layer for inorganic quantum-dot light-emitting diodes. RSC Adv. 9, 11996-12000 (2019).

\section{Acknowledgements}

This work was supported by a grant from Kyung Hee Univeristy in 2018 (KHU-20181299). 


\section{Author contributions}

T.Y.K carried out experiment plan, fabrication, measurements, data analysis and manuscript preparation including figures. S.H.P and B.J.K assisted with the analysis related to photodetector. S.B.H., J.H.Y. and J.S.S. assisted with the analysis related to light emitting diodes. J.A.H.. and B.S.K. did the analysis of X-ray photoelectron spectroscopy (XPS) and ultraviolet photoelectron spectroscopy (UPS). Y.D.K, Y.P. and S.J.K. confirmed the draft manuscript. All authors reviewed the manuscript.

\section{Competing interests}

The authors declare no competing interests.

\section{Additional information}

Supplementary Information The online version contains supplementary material availlable at https://doi. org/10.1038/s41598-021-81480-5.

Correspondence and requests for materials should be addressed to Y.P. or S.J.K.

Reprints and permissions information is available at www.nature.com/reprints.

Publisher's note Springer Nature remains neutral with regard to jurisdictional claims in published maps and institutional affiliations.

(c) (i) Open Access This article is licensed under a Creative Commons Attribution 4.0 International License, which permits use, sharing, adaptation, distribution and reproduction in any medium or format, as long as you give appropriate credit to the original author(s) and the source, provide a link to the Creative Commons licence, and indicate if changes were made. The images or other third party material in this article are included in the article's Creative Commons licence, unless indicated otherwise in a credit line to the material. If material is not included in the article's Creative Commons licence and your intended use is not permitted by statutory regulation or exceeds the permitted use, you will need to obtain permission directly from the copyright holder. To view a copy of this licence, visit http://creativecommons.org/licenses/by/4.0/.

(C) The Author(s) 2021 